\section{The author replies.}

We agree with Dr. Macias that the frequency and microbiology of infusion-related infections vary according to nursing and medical practice in various hospitals and countries. Klebsiella infections are not a common cause of infusion-related bacteremia at our institution or in the United States of America in general.

As we concluded in our study, "larger trials are required to determine whether delaying replacement of intravenous administrations sets up to 7 days is safe." Dr. Macías should test this observation in his medical setting before concluding that it is safer to adhere to the "traditional way."

Issam Raad, MD The University of Texas MD Anderson Cancer Center Houston, Texas

\section{Frequency of Intravenous Administration Set Changes and Bacteremia: Defining the Risk}

\section{To the Editor:}

I would like to respond to a comment made by Dr. Robert R. Muder in his editorial, "Frequency of Intravenous Administration Set Changes and Bacteremia: Defining the Risk."1

Dr. Muder stated, "The impetus for increasing the interval (of intravenous tubing changes) is, of course, cost, which includes acquisition cost of the set and nursing time required for routine changes."

It seems to me that one of the goals of intravenous fluid administration should be to maintain a closed system, thereby preventing contamination of the infusate; therefore, it is difficult to separate the issue of when to change the tubing from the issue of when to rotate the site. Several studies have indicated that routine site changes are not necessary at 72 hours. ${ }^{24}$ Having two different time frames for site and tubing creates the situation where the system would have to be opened at the catheter hub, creating a portal of infection for the patient and potentially exposing staff to blood. Research to determine whether extended hang time for fluid and tubing is safe is a natural extension of the research to determine whether extended dwell times for peripheral catheters is safe. Both issues relate to patient comfort and safety.

As an infection control practitioner, my primary goal is always for the safety and comfort of the patients and the staff. If slaying the sacred cow contributes to this, I am satisfied that I have accomplished that goal. If, by slaying the sacred cow, institutions are able to decrease cost, we all benefit.

\section{REFERENCES}

1. Muder RR Frequency of intravenous administration set changes and bacteremia: defining the risk. Infect Control Hosp Epidemiol 2001;22:134-135.

2. Bregenzer T, Conen D, Sakmann P, Widmer AF. Is routine replacement of peripheral intravenous catheters necessary? Arch Intern Med 1998;158:151-156.

3. Homer LD, Holmes KR Risks associated with 72- and 96-hour peripheral intravenous catheter dwell times. I Intraven Nurs 1998;21:301-305.

4. Lai KK. Safety of prolonging peripheral cannula and IV tubing use from 72 hours to 96 hours. Am J Infect Control 1998;26:66-70.

\section{Barbara D. Graeber, BSN, RN Deering Hospital Miami, FLorida}

\section{The author replies.}

I agree with Ms. Graeber that the primary goal of infection control is to promote the safety and well-being of the patient. There is ample evidence in the published literature to indicate that reducing nosocomial infections and other complications is eminently costeffective, so patient safety and cost reduction need not be in conflict. The study by Raad and colleagues evaluated tubing changes in central intravenous lines. ${ }^{1}$ Note that these lines are not usually changed at predetermined intervals but are left in place until they are not needed, they malfunction, or a complication develops; thus, the question of coordinating tubing changes with site rotation is not an issue, nor is patient comfort. However, there is undoubtedly a risk of bacterial contamination associated with breaking the system for a tubing change, which must be balanced with risks posed by prolonged use of the infusion set.

With regard to peripheral intra- venous lines, there is, as Ms. Graeber notes, evidence to suggest that routine site changes at 72 hours may not be needed. Site rotation has been a standard of care for many years, but it has some drawbacks. One of the most important of these is the discomfort associated with a new placement. I think Ms. Graeber's suggestion that future studies evaluate the catheter and tubing as a unit is a very reasonable one. If a well-conducted randomized trial demonstrates that extending the duration of catheter and tubing use is safe, it would lead to improved patient comfort at a lower cost.

\section{REFERENCE}

1. Raad I, Hanna HA, Awad A, Alrahwan A, Bivins C, Khan A, et al. Optimal frequency of changing intravenous administration sets: is it safe to prolong use beyond 72 hours? Infect Control Hosp Epidemiol 2001;22:136-139.

Robert R. Muder, MD

VA Pittsburgh Healthcare System Pittsburgh, Pennsylvania

\section{The Identification and Investigation of Clustered Bacterial Isolates on Nursing Home Units}

\section{To the Editor:}

Infection control reporting in nursing homes usually lists clinical syndromes (eg, respiratory tract or urinary tract infection), room number, and date. ${ }^{1}$ Unfortunately, such listings do not provide much evidence of transmission, since the various infection syndromes may be caused by different organisms and a common strain may produce more than one syndrome (eg, methicillin-resistant Staphylococcus aureas may cause pneumonia and wound infection). ${ }^{2}$ Finally, there may be a time lag between transmission of low-virulence pathogens and a second event, such as aspiration or skin abrasion, that allows the colonizer to produce infection detected by culture. We present a technique that lists bacterial isolates of identical species and antibiotic sensitivity for each nursing unit. Clusters with a possible common source are identified, followed by clinical assessment. This technique provides staff with specific circumstances to review secretion precautions. 